\title{
Muchas copas de oro con muchas piedras preçiosas: joyas, lujo y magnificencia en la Castilla de don Álvaro de Luna*
}

\author{
Fernando ViLlaseñor Sebastián \\ Universidad de Cantabria \\ Departamento de Historia Moderna y Contemporánea \\ villasenorf@unican.es
}

\begin{abstract}
RESUMEN
Don Álvaro de Luna (ca. 1390-1453), fue uno de los personajes más influyentes de la política castellana en época de Juan II. Junto al ejercicio del poder político, su ascendiente sobre el monarca le permitió configurar un patrimonio que no había heredado, y acumular inmensas riquezas. El castillo palacio de Escalona, su residencia principal, fue convertido por él en el arquetipo de residencia nobiliaria siendo el lugar elegido para custodiar parte de sus tesoros. Haciendo uso de las crónicas, los inventarios realizados en 1453 tras su muerte, algunas donaciones efectuadas a ciertos ámbitos eclesiásticos y la propia dotación de su capilla funeraria llevada a cabo por su viuda, 30 años más tarde, el 8 de mayo de 1484, se pretende sistematizar y reconstruir el conjunto de piezas suntuarias que como signo de poder poseyó una de las personalidades más fascinantes del s. XV.
\end{abstract}

Palabras clave: Álvaro de Luna, Castillo de Escalona, Juan II, tesoro, joya.

\section{Muchas copas de oro con muchas piedras preçiosas: Jewelry, Luxury and Magnificence in the Castile of Don Álvaro de Luna}

\begin{abstract}
Don Alvaro de Luna (c. 1390-1453), was one of the most influential figures of the Spanish policy in the reign of John II. His influence over the king allowed him the exercise of the political power, to set a heritage that he had not inherited and accumulated an immense wealth. The castle palace of Escalona, his main house, was converted by him in the archetypal of the noble residence and it was the place for the custody of his treasures. Using the chronic, the inventories made in 1453 after his death, some church donations to certain areas and the endowment of his funerary chapel by his widow, 30 years later, on May 8,1484 , the main objective of this article is to systematize and rebuild the sumptuary set of pieces which possessed, as a sign of power, one of the most fascinating personalities of the fifteenth century.
\end{abstract}

Key words: Álvaro de Luna, Castle of Escalona, Juan II, treasure, jewel.

\footnotetext{
* Esta investigación se enmarca dentro del proyecto del Plan Nacional I+D+i “Arquitectura Tardogótica en la Corona de Castilla: Trayectorias e Intercambios" (ref. HAR2011-25138).
} 
Don Álvaro de Luna (ca. 1390-1453), "alcançó tanto en Castilla, que no se falla por corónicas que honbre tanto alcanzase, ny tan grande poderío touviese, ni tanto amado fuese de su Rey como él hera" ${ }^{1}$. Numerosos testimonios reflejan su inmensa riqueza ${ }^{2}$, $\mathrm{y}$, en varias ocasiones, se afirma que "tenía en su casa, a los quales daua dineros, tres mill honbres darmas, e fizo muchos bienes a parientes e criados suyos, e ayudó a otros muchos del rreyno"3. La meteórica carrera que desarrolló a partir de 1420 le permitió adquirir un creciente patrimonio y acumular una gran cantidad de riquezas ${ }^{4}$. Además, el maestre de Santiago estimaba las ropas y las joyas, y las crónicas mencionan diversos momentos en que fue el árbitro de la moda en la corte ${ }^{5}$; llegándose a afirmar que "Vistiose siempre bien, é assi le estaba bien lo que traía, que si se vestía de monte, ó de guerra, ó de arreos, á todos parescía bien"6.

A pesar de que don Álvaro de Luna, se consideraba un declarado seguidor de Séneca, que cifraba la virtud en la pobreza ${ }^{7}$, la realidad aportada por los documentos ha llevado a los historiadores a insistir en el enriquecimiento y acumulación de rentas y títulos debido a la influencia que el Condestable ejerció sobre el monarca. Sin embargo, la resolución de este aparente conflicto, la honestidad de la riqueza, la consigue al distinguir entre la hacienda bien ganada y provechosamente gastada de aquellas riquezas que no gozan de esta consideración. Para el privado, las tareas de gobierno son el más alto fin a que puede dedicarse un hombre, por lo que el dinero acumulado a través de la gestión pública y empleado en fines políticos podía considerarse un ins-

1 P. CARRILlo DE HUETE, Crónica del Halconero de Juan II de Castilla, J. DE MATA CARRIAZO (ed.), Madrid, 1946, p. 176.

2 La Crónica del Halconero de Juan II de Castilla, en su Capítulo CLXXIII: "De los heredamientos que tenía el condestable", sostiene que, ca. 1434, "hera condestable de Castilla e conde de Santesteuan, e después fue maestre de Santiago, e camarero del Rey, y de la cámara de los paños, e era señor de Ayllón e de su tierra, e de Riaza e su tierra, e de Castilnobo e de la suya, e señor de San Martin de Valdeyglesuas, e señor de Cadahalso, e de Escalona e su tierra, e de Maqueda e de su tierra, e señor del Castil de Vayuela, e señor de Montalbán e de su tierra, e señor de Arenas, e señor del Colmenar, e señor de Cornago e de Jueca e de Quéllar, e de Alborquerque e de Azagala", p. 178.

3 J. DE MATA CARRIAZO, op. cit., 1946, p. 177.

4 A. RUCQUOI, "Privanza, fortuna y política: la caída de Álvaro de Luna", Rex, Sapientia, Nobilitas, Estudios sobre la Península Ibérica medieval, Granada, 2006, p. 330. La versión original del artículo es "Privauté, Fortune et politique: La chute d'Álvaro de Luna", Der Fall des Günstlings. Hofparteien in Europa vom 13. Bis zum 17 Jahrhundert, Stuttgart, 2004, pp. 287-310.

5 Crónica de don Álvaro de Luna, Condestable de Castilla, Maestre de Santiago, J. DE MATA CARRIAZO (ed.), Madrid, 1940, pp. 20, 29, 53, 67-68, 207-208 y 329. A. RUCQUOI, op. cit., 2006, p. 334. Veáse E. FERNÁNDEZ GONZÁLEZ, "Don Álvaro de Luna, Condestable de Castilla y Maestre de Santiago: hombre de su tiempo y promotor de las artes”, La Nobleza Peninsular en la Edad Media, Ávila, 1999, pp. 137-163.

6 J. DE MATA CARRIAZO, op. cit., 1940, capítulo LXVIII: "De la figura e fechura de don Álvaro de Luna, Maestre de Santiago, é de las sus maneras é costumbres”, p. 207.

7 J. AMADOR DE LOS RÍOS, "El condestable don Álvaro de Luna y sus doctrinas políticas", II Revista de España, XIX (1871), p. 477; J. MARICHAL, La voluntad de estilo. Teoría e historia del ensayismo hispánico, Madrid, 1971, p. 35; y F. CASTILLO CÁCERES, "El tesoro de don Álvaro de Luna en el Castillo de Escalona”, Numisma, 235 (1994), pp. 61-75, publicado con el mismo título en F. CASTILLO CÁCERES, Estudios sobre cultura, guerra y política en la Corona de Castilla (siglos XIV-XVII), Madrid, 2007, p. 274. 
trumento para ganar la virtud ${ }^{8}$. Y ciertamente, como ha señalado Rucquoi, Álvaro de Luna utilizó su ascendiente sobre Juan II, sobre todo, para ejercer ese poder político9.

No obstante, ello no impidió que gustase del lujo, la ostentación y el empleo de elementos suntuarios propios de la cultura aristocrática tardomedieval, buscando, incluso a través de ellos, reforzar su poder y prestigio personal ${ }^{10}$; ya que -como indica Max Weber-, el carácter público que acompaña el despliegue del lujo es un medio idóneo para la elevación de la consideración social ${ }^{11}$. Todo ello terminaba el Viernes Santo de 1453, cuando el privado hizo matar uno de sus hombres de confianza, el contador mayor Alfonso Pérez de Vivero tras haberlo traicionado. Unos días después, el rey ordenó que se detuviera al Condestable, posteriormente a sus partidarios, y se procediera a la confiscaron de sus bienes. A finales de mayo, un tribunal condenó in absentia al reo a pena de muerte ejecutándose la sentencia en Valladolid el 2 de junio $^{12}$.

Haciendo uso de las crónicas, los inventarios realizados en 1453 tras su muerte, algunas donaciones efectuadas a ciertos ámbitos eclesiásticos y la propia dotación de su capilla funeraria llevada a cabo, treinta años más tarde, el 8 de mayo de 1484, por doña Juana Pimentel -incluyendo casullas, amitos, cintas de seda, albas, manípulos, estolas, dalmáticas, frontales ricos con las armas de los Luna, corporales, sábanas de altar, cruces de plata, un cáliz con su patena que tiene en el pie labradas escenas de la pasión, otro cáliz de menor peso, dos candelabros de plata y unas vinajeras del mismo metal, un misal toledano en pergamino y, sobre todo, la renta suficiente para que se mantuvieran tres capellanías-, se pretende sistematizar y reconstruir el conjunto de piezas suntuarias que como signo de poder poseyó una de las personalidades más fascinantes del s. XV castellano.

\section{Testimonios cronísticos}

Tras la muerte de Catalina de Lancaster el 2 de junio de 1418, en marzo del año siguiente, Juan II fue declarado mayor de edad con catorce años en las Cortes de Madrid. Con ocasión de las fiestas, torneos y justas que se celebraron, el 6 de marzo de 1419 ,

8 ÁlVARO DE LUNA, Libro de las claras e virtuosas mujeres, Madrid, 1891, pp. 9 y 176; J.A. MARAVALL, Estado Moderno y Mentalidad Social, Madrid, 1972, t. 2, p. 109; O. DE CAMILLO, El humanismo castellano del siglo XV, Valencia, 1976, p. 178, nota 78; y F. CASTILLO CÁCERES, op. cit., 2007, p. 274.

9 A. RUCQUOI, op. cit., 2006, p. 331.

10 F. CASTILLO CÁCERES, "El castillo-palacio de Escalona, corte y escenario de poder de Álvaro de Luna", La Fortaleza Medieval: Realidad y símbolo, 1998, p. 268.

11 M. WEBER, Economía y sociedad, México, 1977, II, p. 844. Cit. por F. CASTILLO CÁCERES, op. cit., 1998, p. 272. Siguiendo a Elías Norbert (E. NORBERT, La sociedad cortesana, Madrid, 1993, p. 75), Castillo insiste en cómo el lujo cortesano y nobiliario es un fenómeno de intenso contenido social; donde, la vivienda, junto con el vestido, es una manifestación primaria y esencial de lo denominado consumo de prestigio y, de este modo, el lujo medieval va a tener una característica pública dominante.

12 A. RUCQUOI, op. cit., 2006, p. 337. 
“Don Álvaro de Luna avia salido á la justa muy ricamente armado, é con unos paramentos muy ricos, é llevaba assimismo aquel dia una joya de su amiga de unas tranzaderas de oro é seda, que le ceñian por las espaldas, é por encima de la vuelta del escudo (...). E Don Alvaro avia grand voluntad de lo facer muy bien aquel dia, assi por le mirar el Rey su señor, como muchas dueñas e doncellas, é grandes señoras que alli estaban, é por amor que de la joya que de su amiga llevaba"13.

El nombramiento como Condestable de Castilla, el 10 de diciembre de 1423, implicó la entrega del bastón de la justicia, con un valor más simbólico que propiamente material $^{14}$. Sin embargo, al relatar las fiestas que se celebraron en Tordesillas, con motivo del acontecimiento, se pone de manifiesto la propensión al lujo que va a caracterizar a don Álvaro:

"E todos los caballeros e escuderos e pajes de la casa del Condestable, en la cual avia muchos fijos de condes, é de grandes honbres, é personas principales, procuraron de salir muy ricamente vestidos é arreados á las fiestas e justas, e seruir muy nueva e apuestamente en todos los otros entremeses.

Alli fueron sacadas ropas muy ricas, ca el Condestable había dado á todos ropas de seda; é allí salieron bordaduras e invenciones de muy nuevas maneras, e muy ricas cintas, e collares, e cadenas, e joyeles de grandes prescios, e con finas piedras e perlas, e muy ricas guarniciones de caballos e facaneas, en tal manera que toda aquella corte relumbraba e resplandecía" 15 .

En 1427, una liga encabezada por los infantes de Aragón hacía efectivo el exilio de Álvaro de Luna en Ayllón y la creación de un Consejo Real dominado por el rey de Navarra. Sin embargo, su vuelta se producía al año siguiente ${ }^{16}$, y para la misma

"Non fué de pequeño prescio el arreo e rico guarnecimiento que para el Condestable, é los caballeros é escuderos de su casa se adereszó, é fizo para aquella entrada en la corte. Alli fueron traidos plateros, argenteros, é bordadores, é sastres de la corte del Rey, é aún fuera del Regno, los cuales muchos días fueron ocupados en facer guarniciones de oro é de plata, é cintas, é cadenas, é ropas, e otras borduras muy ricas, quales antes no habían parecido en la corte" ${ }^{17}$.

13 J. DE MATA CARRIAZO, op. cit., 1940, capítulo VIII: “Como iba cresciendo Don Álvaro de Luna en estado é virtudes, é cómo fue ferido en Madrid en la justa el día que entregaron el Regno al Rey”, p. 29.

14 Ibid., capítulo XIV: "Como el Rey de Castilla fizo su Condestable al conde Don Álvaro de Luna, é de las fiestas que él fizo al Rey e a su corte”, p. 52.

15 Ibid., p. 53.

16 El regreso del Condestable originó una guerra entre Aragón y Castilla. En julio de 1430, la firma de la tregua sancionó la victoria de Luna, condenando al exilio a los infantes de Aragón y el poder de don Álvaro no paró de aumentar de 1430 a 1439. L. SUÁREZ FERNÁNDEZ, Nobleza y monarquía. Puntos de vista sobre la historia politica castellana del siglo XV, $2^{\mathrm{a}}$ edición, Valladolid, 1975, pp. 109-179; A. RUCQUOI, op. cit., 2006, pp. 328-329.

17 J. DE MATA CARRIAZO, op. cit., 1940, capítulo XVII: "De los debates e bollicios que avia en la corte entre los grandes que en ella estaban, e estando el Condestable fuera de ella: é como siendo rogado volvió á la corte: é como fue rescebido en ella", p. 67. 
La Crónica prosigue señalando cómo se produce su entrada

"En esta guisa guarnido é adereszado con su gente, el Condestable iba a entrar en la corte, é antes que con una legua llegase á Turegano, salian ya muchas gentes á lo rescebir" 18 .

La llegada a la localidad segoviana donde estaba la Corte, se hizo efectiva el 6 de febrero de 1428, y la Crónica del Halconero de Juan II de Castilla, al relatarla, describe, igualmente, con una gran precisión el modo en que los "grandes, perlados y hombres de estado" que lo acompañaron iban vestidos, incidiendo también en la riqueza de la indumentaria de don Álvaro y describiendo de que forma era acompañado el condestable por sus pajes:

"E estos venían tan bien guarnidos, así de sus personas como de cavallos e pajes, que omes que aquellos vieron abía gran tiempo que nunca en Castilla otros tan bien guarnidos vieron. Que todos venían bordados de azeytuny e de argentería: de la manera que ellos venían, asy venían sus pajes.

E el condestable venía vien bordado de argentería, e quatro pajes por aquella vía, e quatro caballos muy grandes e muy hermosos, e muy bien guarnidos e maravilla $\mathrm{E}$ venían delante dél dos negros, que traían sendos lebreles negros; e el vno traya un venado, e el otro traya vna lança de Xeréz" ${ }^{19}$.

A primeros de mayo de 1435, Juan II va a la villa de Escalona y la Crónica describe cómo

"El domingo fizo el su condestable sala, e mandó rraçiones a todos los que con él venían; e jugaron cañas ese día, e fezieron muy vuena fiesta. E teníanle muy vien guarnidas las salas de paños françeses, e camas, vien a marauilla" ${ }^{20}$.

Un mes más tarde, el 24 de junio de 1435, en Madrid, se produjo el nacimiento de Juan de Luna, primer hijo de su matrimonio con Juana Pimentel, y el 3 de julio

"fue vateado (bautizado) en las casas de Alfonso Álvarez, contador, donde el condestable posaba. E la pila era vna grande vaçina, do acostunbrauan vañarse las dueñas, toda guarnida de paño de oro en derredor" (...) "e dio el Rey a la condesa vn diamante e vn rrobí que fue apreciado en tres myll florines" 21.

En noviembre de 1435, durante las fiestas que Juan II hizo en honor de su hermana la reina María de Aragón

18 Ibid., p. 68.

19 Ibid., Capítulo I: "De la entrada del condestable en Turuégano", p. 18.

20 J. DE MATA CARRIAZO, op. cit., 1946, capítulo CLXXX: "De cómo partió el Rey en rromería, a Santa María de Gadalupe", p. 197.

21 Ibid., capítulo CLXXXIV: "De un hijo que nasçió al condestable", p. 211. La Crónica... (J. DE MATA CARRIAZO, op. cit., 1940) en el capítulo XLIII: "De cómo le nasció un fijo al Condestable de la Condesa su muger fija del Conde de Benavente, que ovo nombre don Juan", p. 147, se hace eco de la misma noticia. 
"su condestable don Áluaro de Luna fizo grandes conbites, así la rreyna como a todos los señalados hombres que con ella venían, e dióles mulas e otras cosas que se acostumbrauan dar los tales hombres como él en las tales fiestas como estas" 22 .

El 17 de agosto de 1447, Juan II contrae matrimonio con su segunda esposa, Isabel de Portugal, y el Condestable presta algunas de sus joyas al monarca para que las usara en la boda. De estas, la primera que se menciona es "un joyel que se llama de la Serena que es fecho en figura de una doncella e tiene un rubí grande e debaxo del rubí una esmeralda grande con dos perlas grandes a manera de peras". Hay otro joyel, igualmente rico, y un tercero "que se llama la prensa en que está un diamante punta mayor que es una avellana con su cáscara" ${ }^{23}$.

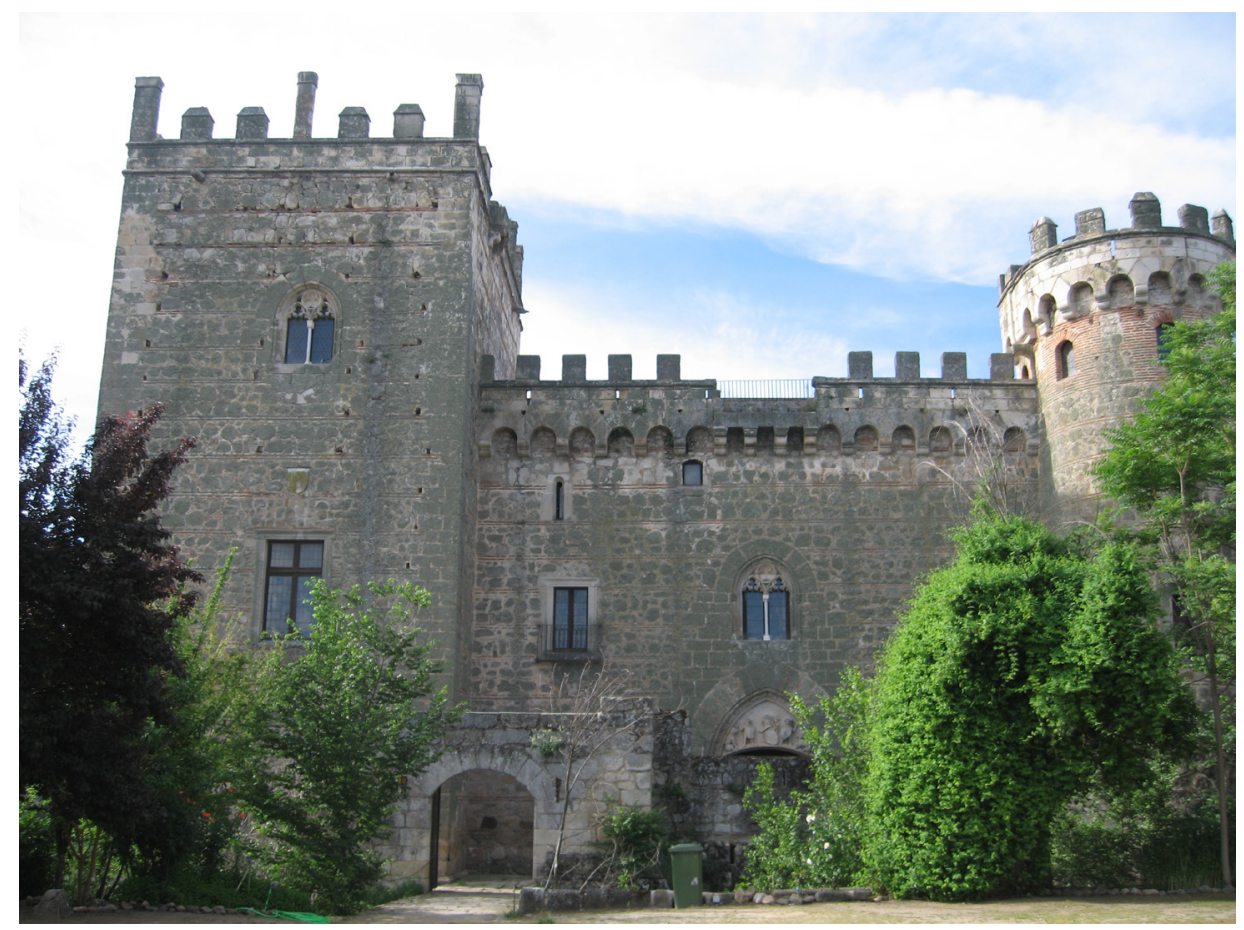

Fig. 1. Castillo-Palacio de Escalona. Fachada principal.

El mayor testimonio de lo expuesto con anterioridad, sin duda, lo supone, las fiestas organizadas en el castillo-palacio de Escalona (donde "los continuos de su casa

22 J. DE MATA CARRIAZO, op. cit., 1946, capítulo CXCII: “de las fiestas e dádivas que el rey fizo a la rreyna su hermana", p. 18.

23 J.M. CALDERÓN (ed.), Álvaro de Luna (1419-1453). Colección diplomática, Madrid, 1999, 1447, doc. 116, p. 364; J. YARZA LUACES, La nobleza ante el rey. Los grandes linajes castellanos y el arte en el siglo XV, Madrid, 2003, p. 79, sostiene que "se trataría de una de esas joyas de diseño imaginativo que tanto se fabricaron en Francia en el entorno de 1400”. 
siempre estaban bien adereçados e guarnidos para las semejantes neçesidades") $)^{24}$ (Fig. 1), en 1448, cuando acudió el rey junto con Isabel de Portugal, con un grupo de embajadores portugueses en el séquito. Uno de los aspectos más interesantes es la descripción de la Sala Rica, cubierta como el resto de la casa de tapices franceses, y con aparadores para mostrar las piezas de orfebrería y la vajilla expuesta en las repisas y otros objetos preciosos que pertenecían al Condestable; en aras de conseguir la teatralidad y magnificencia ${ }^{25}$ propia de la vida social del s. XV. La Crónica relata cómo

"Después que entraron dentro de la casa, falláronla muy guarnida de paños françeses, e de otros paños de seda e de oro, e muy ordenada de todas las cosas que conbenían: é todas las cámaras e salas estaban dando de sí muy suabes olores.

Las mesas estaban ordenadas, e puesto todo lo que convenia a serbiçio dellas: é entre las otras mesas sobian unas gradas fasta una mesa alta, el cielo é las espaldas della era cobierto de muy ricos paños de brocado de oro fechos a muy nueva manera (...). Los aparadores do estaban las baxillas, estaban a la otra parte de la sala, en las cuales avía muchas gradas cubiertas de diversas piezas de oro e de plata: é donde avia muchas copas de oro con muchas piedras preçiosas, é grandes platos, é confiteros, é barriles, é cantaros de oro é de plata cobiertos de sotiles esmaltes é labores.

Aquel día fué servido el Rey allí con una copa de oro, que tenía en la sobrecopa muchas piedras de grand valia, e de esmerada perfiçion: la qual la çibdad de Barcelona ovo presentado entre otros dones al Maestre, quando a él ovo enviado sus enbaxadores, deseando su amor e amistad, oyendo dezir sus grandes fechos é virtudes" ${ }^{26}$.

La pieza descrita, copa de oro con sobrecopa y piedras preciosas, debió ser una de las más singulares en posesión del Condestable, al permitir su uso al monarca. Otro aspecto destacable es su origen barcelonés, con una larga tradición orfebre desde el s. XIV, que ponen de manifiesto joyas de exótica factura como el castillo de amor de Pedro IV $^{27}$ y la existencia de importante plateros -Marcos Canyes, Marcos Olzina o Bernardo Llopart- durante la primera mitad del s. XV. Estos realizaban numerosas creaciones entre las que destacaban las vajillas con el escudo de la ciudad que se utilizaban de regalo a personalidades como sucede con el propio Condestable ${ }^{28}$.

Además, resulta esclarecedor señalar, cómo las crónicas también hacen referencia a la presencia de camareros - esto es, encargados del mantenimiento de la Cámara del señor, plata, joyas, objetos preciosos y dinero- entre los cargos domésticos de la casa

24 J. DE MATA CARRIAZO, op. cit., 1940, capítulo LXXIV: “Como el Maestre sopo de la venida del Rey é de la Reyna, e del rescebimiento e fiestas que en Escalona les fizo”, p. 217.

25 Sobre el concepto de "Magnificencia" a finales de la Edad Media, vid. el artículo de B. ALONSO RUIZ, "La Nobleza en la ciudad: Arquitectura y Magnificencia a finales de la Edad Media", Studia Historica. Historia Moderna, 34 (2012), pp. 215-251, esp. 216-221.

26 J. DE MATA CARRIAZO, op. cit., 1940, pp. 219-220.

27 J. YARZA LUACES, "Reflexiones sobre lo fantástico en el arte medieval español", Formas artísticas de lo imaginario, Barcelona, 1987, p. 14; F. CASTILLO CÁCERES, op. cit., 1998, p. 277, nota 66.

28 S. ALCOLEA, Artes decorativas en la España Cristiana (siglos XI-XIX), vol. XX de Ars Hispaniae, Madrid, 1975, pp. 144-145 y 159; y F. CASTILLO CÁCERES, op. cit., 1998, p. 277, nota 66. 
de don Álvaro ${ }^{29}$; conociendo el nombre de dos de ellos: Fernando de Ribadeneira ${ }^{30} \mathrm{y}$, desde 1446, Gonzalo Chacón ${ }^{31}$.

\section{El tesoro y su confiscación}

Desde finales del s. XIX, las riquezas atesoradas por Álvaro de Luna recibieron atención historiográfica ${ }^{32}$; y uno de los momentos que más han destacado los historiadores ha sido la manera en que el Condestable, en el momento final de su vida y ante la forma en que se estaban desarrollando los acontecimientos, distribuye por diferentes lugares -Montiel, San Esteban de Gormaz, Portillo- episodio que la Crónica refiere del siguiente modo:

"Antes su voluntad era, queriéndose proveer e remediar para en lo advenidero, segúnd las cosas andaban engolfadas en golfos de bien tempestuosas e peligrosas ondas, e tenía deliberado de enviar a aquella fortaleza de Montiel todos los tesoros que tenía en la su fortaleza de Escalona, e quitarlos de en medio del reyno" 33

“(...) de guisa que todavía sería más sano e más seguro que aquellas arcas de moneda de oro se lebasen a la fortaleza de Santesteban (...). Más en efecto, todavía el Maestre quiso, e mandó que fuesse el Françisco de León, e otro criado del mismo Gonçalo Chacón, de quien él mucho fiaba, a llevar a Portillo aquel tesoro" ${ }^{34}$.

"mandó traer los manteles, ca era ya hora de comer, e mándolos poner ençima de tres arcas de moneda de oro que en ellas estaba. E puestas aquellas arcas la una sobre la otra en medio de su cámara, mandó traer de comer, por çierto su plato muy costoso, e muy abastado (...)"35.

29 F. CASTILLO CÁCERES, op. cit., 1998, p. 273.

30 J. DE MATA CARRIAZO, op. cit., 1946, pp. 158, 281-283 y 512.

31 F. CASTILLO CÁCERES, op. cit., 1998, p. 273.

32 P.M. BARREDA, Sepulcro de don Álvaro de Luna en la capilla de Santiago de la Catedral de Toledo, Madrid, 1882, ya afirma que "tenía cuando murió, sin contar vajillas de oro y plata, un millón y medio de doblas de la banda, y de monedas de Aragón y de otras partes ochenta cuentos y siete tinajas de doblas alfonsíes y florentinas..." (pp. 25-26; aporta la referencia E. FERNÁNDEZ GONZÁLEZ, op. cit., 1999, p. 161). N. ROUND, The greatest man uncrowned, Londres, 1986, p. 233, sostiene su elevada valoración y el deseo de Juan II de apoderarse de ellos como una de las principales causas de caída y ejecución del valido; A. FRANCO SILVA, "La villa toledana de Escalona. De Don Álvaro de Luna a los Pacheco", Estudios de Historia y Arqueología, X (1994), pp. 52-53 (de gran interés también A. FRANCO SILVA, "El destino del patrimonio de don Álvaro de Luna, problemas y conflictos en la Castilla del siglo XV", Anuario de Estudios Medievales, 12 (1982), pp. 549-584); I. PASTOR BODMER, Grandeza y tragedia de un valido. La muerte de Don Álvaro de Luna, Madrid, 1992, vol. II, documentos, pp. 367-368; y J.M. CALDERÓN ORTEGA, Álvaro de Luna: riqueza y poder en la Castilla del siglo XV, Madrid, 1998, pp. 284-292.

33 J. DE MATA CARRIAZO, op. cit., 1940, capítulo CIV: "De los fechos que passaron en Tordesillas en tanto que el Rey alli estovo", p. 311.

34 Ibid., capítulo CXII: "De algunos modos que el ýnclito Maestre tovo e buscó para se reparar en sus fechos, segúnd los términos en que pendían", p. 341.

35 Ibid., capítulo CXXII: "De cómo vinieron a fablar con el Maestre Ruy Díaz de Mendoça e el obispo de Burgos, e de las seguridades que el Rey le dió; e de otras algunas cosas que pasaron tocantes a la Historia", p. 397. 
"E dixo otrosí que el oro e la plata, e las joyas, e las otras cosas, e las joyas que allí tenía, lo cual todo por çierto era de muy grand valía, él lo dexaba al Rey su señor, si por ventura su Alteza quisiese disponer dél" 36

Juan II quiso apoderarse de los tesoros de oro y joyas que estaban en Portillo, el monasterio de la Armedilla de Cuellar y Escalona ${ }^{37}$; algo que respondía, según Castillo y Cáceres, a una codicia generaliza en la época donde, el afán de lucro en base a la posesión de metal amonedado había sustituido a la mera acumulación de oro y plata $^{38}$. El testimonio aportado por León del Corral ${ }^{39}$, a través del llamado manuscrito de Zarauz, lo deja claro, así como, tras la ejecución, el monarca se ocupa de entrar en contacto con el heredero y su viuda para llegar a un acuerdo en junio de 1453 según el cual Juana Pimentel debía entregar todo el tesoro de dinero y joyas al rey para que este haga tres partes; confiscando dos, devolviendo la tercera a la viuda y la confirmación de que a su hijo Juan de Luna se le entregarían los señoríos de su padre ${ }^{40}$.

El citado manuscrito es un documento hallado en la casa de Corral de Zarauz y se trata de un apuntamento de la probanza hecha por el Marqués de Villena; estando cotejado con el proceso original por los relatores Sanz, Guedeja y Santander, y presentado al Consejo Real por el contador Juan de Valera en nombre del Marqués. Y que no lleva fecha ${ }^{41}$.

PREGUNTA XXX ${ }^{42}$.-Se pregunta si, ejecutada la sentencia, el Rey procuró apoderarse de los bienes del Condestable, reteniendo unos y haciendo merced de otros a quien le plugo:

Figuran 20 declaraciones.

Testigo IV.- ...que saue e vido que el mesmo dia que prendieron en Burgos al dho condeestable don Albaro de Luna, el dho señor rrei don Juan fue a comer a la casa de Pedro de Cartaxena donde el dho condeestable posaba, y antes que comiese le truxeron delante beinte mill doblas de oro, e toda la plata que dho condeestable allí tenía.

36 Ibid., p. 399.

37 Sobre este, centrado en aspectos monetarios, F. CASTILLO CÁCERES, op. cit., 1994, pp. 61-75; que lo define por la variedad de piezas, que ponen de manifiesto el carácter atlántico y mediterráneo de la economía castellana, y el absoluto dominio del oro. Una reciente revisión en M.M. ROYO MARTÍNEZ, "La moneda castellana en época de don Álvaro", O. LÓPEZ GÓMEZ (coord.), Don Álvaro de Luna y Escalona. Poder, propaganda y memoria histórica en el otoño de la Edad Media, Toledo, 2013, pp. 233-241.

38 W. SOMBART, El burgués, contribución a la historia espiritual del hombre económico moderno, Madrid, 1972, pp. 35-38. Citado por F. CASTILLO CÁCERES, op. cit., 1998, p. 276.

39 L. DEL CORRAL, Don Álvaro de Luna según testimonios inéditos de la época, Valladolid, 1915, pp. 99100. Recogen la información I. PASTOR BODMER, op. cit., 1992, p. 250 y E. FERNÁNDEZ GONZÁLEZ, op. cit., 1999, p. 162.

40 A. FRANCO SILVA, op. cit, 1994, p. 53; J.M. CALDERÓN, op. cit., 1999, doc. 136, p. 406.

41 Es un manuscrito en folio, todo de una letra: letra gruesa de principios del s. XVI, especie de procesal muy cuidada y sin encadenar, como se usó mucho tiempo en estos documentos, sobre todo cuando se les quería dar cierta solemnidad. El manuscrito se compone de 219 folios, y comprende, además del encabezamiento y la cláusula final, tres series de preguntas o interrogatorios que parecen ser tomadas de distintos pleitos $-\mathrm{o}$ de diversos incidentes de un mismo pleito-, pero manifiestamente de épocas diferentes. El primer interrogatorio comprende 44 preguntas, 21 el segundo y 7 el tercero; y además viene una declaración suelta de Don Álvaro de Luna, el Viejo, que se dice que incoó uno de estos pleitos.

42 Fol. 116. 
E su alteça mandó poner recabdo en ello. E después de esto e antes que el dho condeestable fuese degollado, oyera dezir como el dho señor rrei abía ido para Portillo e la tomara, que era de el dho condeestable, e veynte mill doblas que dezían que tenía en la fortaleça de ella. Y ansi mesmo oyera dezir que, después de degollado el dho condestable, el dho señor rrey tomara la villa de Escalona e las otras villas e fortalezas que fueron de el dho condeestable, e se partieran en tres partes los tesoros que el dho condeestable tenía en Escalona, tomando para si el dho señor rrei dos, e dando la una parte de ellas a la condesa de Montalvan, muger de el mesmo condestable... ${ }^{43}$

Desde junio de 1453 hasta diciembre se suceden los repartos, como ponen de manifiesto diversos documentos ${ }^{44}$. Por lo que respecta a las alhajas, existe la relación proporcionada por el obispo González de la Hinojosa ${ }^{45}$ acerca de los diversos objetos -siete mil paños franceses, doscientas cercaduras de cama, cuatro mil colchones, mil quinientas alfombras, bajillas de oro de trescientos marcos-, y las monedas existentes en la fortaleza de la villa toledana -doblas de la banda (millón y medio); blancas viejas y florines de Florencia, florines de Aragón, doblas alfonsís (siete tinajas) o nobles y ducados-.

Junto a esta, se encuentra la noticia de las piezas inventariadas por Alfonso de Illescas, funcionario real, dando fe de lo hallado en el alcázar de Escalona en el inventario efectuado durante del proceso de incautación llevado a cabo tras la ejecución del valido. Tanto las cantidades monetarias -469 doblas alfonsís, 202 nobles, 3 francos de pie, 42 piezas de diferentes cuños entre los que destacan los florines, ducados y genovinos, dando un total de 716 monedas de oro-, analizadas por Castillo Cáceres ${ }^{46}$, como las diversas joyas, se conocen a través de dos documentos que reproducen la citada relación, con un destacado valor descriptivo: Recamara de Juan II. Joyas del Rey y de D. Álvaro de Luna (Valladolid, Archivo General de Simancas (AGS), Casa

43 L. DEL CORRAL, op. cit., 1915, pp. 99-100.

44 Estos no solo se limitaron a los bienes materiales y suntuarios sino también a las posesiones patrimoniales. E1 26 de junio de 1453 Juan II despachaba un privilegio a Juan de Luna, por el cual le confirmaba la posesión del condado de San Esteban de Gormaz (A. FRANCO, El señorío toledano de Montalbán de Don Álvaro de Luna a los Pacheco, Cádiz, 1992; A. FRANCO SILVA, op. cit., 1994, p. 53). Cuatro días más tarde, Juana Pimentel recibía las villas de La Adrada, Colmenar, Castil de Bayuela, Arenas de San Pedro, La Higuera, San Martín de Valdeiglesias, Villar del Prado, Alamín, la Torre de Esteban Hambrán y La Puebla de Montalbán (Toledo, Archivo Histórico Nacional (AHN), Osuna, leg. 1735, números $3^{1-2}$ y $2^{1-5}$; A. FRANCO SILVA, op. cit., 1994, p. 53). El 12 de julio Juan II concedía a D. Juan de Luna las tercias de Alcocer, Salmerón, Valdeolivas y San Pedro Palmiches (AHN, Osuna, leg. 1724, no 10 1-2; A. FRANCO SILVA, op. cit., 1994, p. 53). Para la Corona quedaba las alcabalas, el pedido y la moneda forera de las villas del Infantado, entregando Juana Pimentel al monarca las joyas y piedras preciosas de don Álvaro y las fortalezas de Alburquerque, Trujillo, Azagala, Montánchez y Escalona. Los acuerdos fueron notificados por el rey el 24 de agosto de 1453, a través de una cédula que dirigió a las justicias del reino (AHN, Osuna, leg. 1724; A. FRANCO SILVA, op. cit., 1994, p. 53).

45 "Continuación de la Crónica de España del Arzobispo don Rodrigo Jiménez de Rada por el Obispo don Gonzalo de la Hinojosa", Colección de Documentos Inéditos para la Historia de España, t. 106, p. 136. Citado por J. FERRANDIS, Datos documentales para la Historia del Arte español. Inventarios Reales (Juan II a Juana la Loca), Madrid, 1943, pp. XII y XIII.

46 F. CASTILLO CÁCERES, op. cit., 1994. 
Real, Escribanía Mayor, Leg. 1, $\left.1^{\circ}\right)^{47}$ y Lo que se dio a Juan II en Escalona del tesoro y joyas del Maestre y condestable don Álvaro de Luna (Madrid, Biblioteca Nacional, colección T. González, Ms. 19710) ${ }^{48}$, cuya relación de piezas y reparto sucesivo de las mismas se reproducen a continuación:

En 25 de junio recibió del mismo Pedro de Astorga que tenía la plata dorada una copa de plata dorada con su sobre copa, fecha de obra enlevada como follages, que pesó quatro marcos e dos onças.

El 26 de junio de dicho año de 1453 el apuntado Alfonso de Illescas recibió en Escalona de la condesa doña Juana lo siguiente:

Treszientas doblas Alfonsíes.

Sesenta y seys nobles y tres francos de pie a una dobla Alfonsí.

Ciento sesenta y ocho doblas Alfonsíes.

Ciento treinta y seis nobles.

Mas otras cuarenta y dos piezas de oro que son ducados e florines de Florencia e Génova e otras monedas 716 piezas de oro

Mas recibió el dicho día tres doblas de las castellanas, una de peso de 25 doblas y la otra de peso de 20 doblas y la otra dobla en moneda de peso de 20 doblas.

Más el dicho día le entregó Pedro de Astorga un collar de oro que fue del Maestre, el qual era fecho de manera escarcolas que pesó seys marcos e una onza e una ochaba.

El 29 de junio recibió mas del dicho Pedro de Astorga lo siguiente:

Seys plateles de oro que pesaron 9 marcos.

Quatro escudillas de oro redondas, que pesaron seys marcos una onza y quatro ochabas.

Un aguamanil de oro que pesó 4 marcos y 1 onza.

Una copa de oro con su sobre copa, que pesó quatro marcos, 6 onzas y 4 ochabas.

Un salero de oro con su tapadero que peso dos marcos e seis onças e dos ochauas.

Un jarro de beril guarnido en oro con su pie e tapadero, que pesó cinco marcos y seis onzas.

Todas esas piezas tenían sus cajas de cuero en que estaban metidas.

El 5 de julio de 1453 se entregaron las siguientes piezas:

47 J. FERRANDIS, op. cit., 1943, pp. 19-24.

48 I. PASTOR BODMER, op. cit., 1992, pp. 367-368. 
Un joyel de oro (en blanco) ${ }^{49}$ esmaltado de esmalte blanco y verde con un balax grande el qual dicho joyel es fecho a manera de rosa.

Otro joye ${ }^{50}$ que se dice del toque que es una bolsa de oro esmaltada de blanco, puesto en la boca della un balax grande e en la dicha bolsa escripta una copla e colgaban de los cerraderos della 24 puntas de toques.

Otro joyel de oro fecho a la manera de cepillo, con dos diamantes en él ${ }^{51}$ el uno punta e el otro rosa e un rubí en el medio de los dichos diamantes e cinco perlas gruesas, las tres de ellas puestas (borroso) ${ }^{52}$ en el dicho joyel, fechas a manera de perillas e las otras dichas perlas, son redondas e con unos temblantes que cuelgan de las dichas perlas, esmaltados de esmalte verde e azul.

Item mas, un diamante grande en punta engarronado en un garçon de oro $^{53}$.

En 22 de Diciembre del dicho año 1453, envió al señor Rey la condesa doña Juana un vaso de beril, con su pie de plata dorado e bebedero de plata asi mesmo dorado e con su sobre copa del mismo beril, guarnida de plata dorada, la qual dicha sobre copa tiene encima un leoncico pequeño con vela de plata dorada. Metida en una caja de cuero blanco.

Los precios a que se tasó la plata dorada de la señora condesa, de su tercera parte son los siguientes:

\begin{tabular}{|c|c|}
\hline 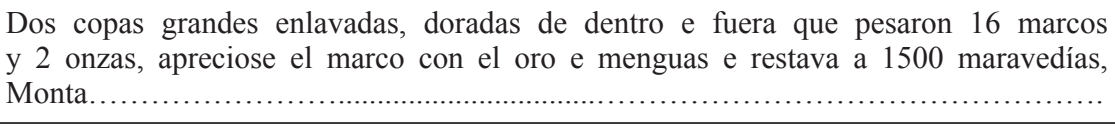 & 24.375 \\
\hline 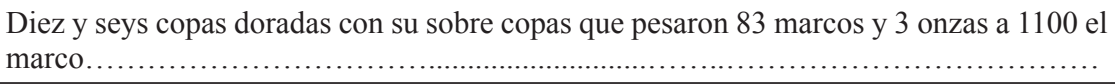 & 91.712 \\
\hline 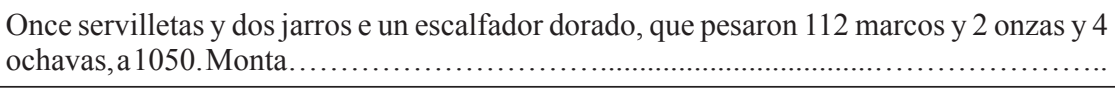 & 117.315 \\
\hline 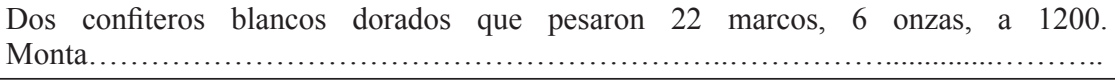 & 27.300 \\
\hline 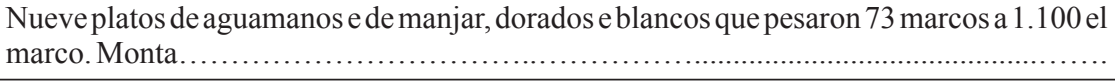 & 80.300 \\
\hline 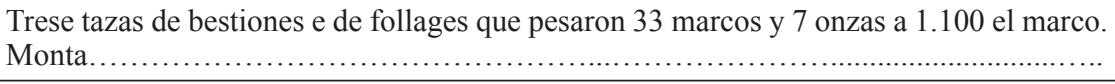 & 37.100 \\
\hline 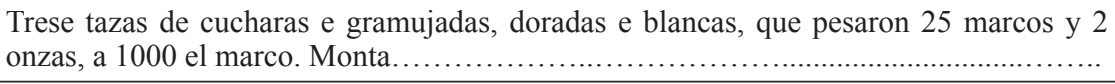 & 29.290 \\
\hline 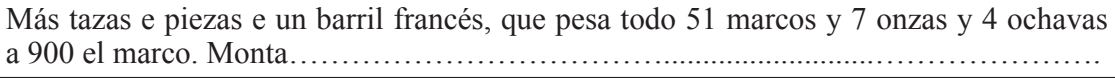 & 46.744 \\
\hline
\end{tabular}

Si las crónicas en los pasajes referidos describen la existencia de un gran número de piezas (collares, cadenas, joyeles, perlas, piedras preciosas, paños franceses, de

49 El inventario aportado por J. FERRANDIS, op. cit., 1943, p. 19, precisa que es "redondo".

50 Al margen: diose al infante don Alfonso, que el señor Rey le mandó dar.

51 El inventario aportado por J. FERRANDIS, op. cit., 1943, p. 19, precisa que son "grandes".

52 El inventario aportado por J. FERRANDIS, op. cit., 1943, p. 19, precisa "por pinjantes".

53 Ibid., p. 19. 
seda y de oro, joyas con rubís, esmeraldas, perlas, diamantes -algunos incluso tallados en forma de avellana con su cáscara-, vajillas con piezas de oro y plata, copas de oro con muchas piedras preciosas -destacando una con soprecopa-, grandes platos, confiteros, barriles, cantaros de oro y plata cubiertos de esmaltes y, probablemente, labores de filigrana); todas ellas son referidas en los citados inventarios, destacando la existencia también de un aguamanil y un salero (metidos en cajas de cuero); joyas esmaltadas a manera de rosas, escalfadores o tazas con follajes.

No hay que desdeñar tampoco, la intención expositiva de algunas de las piezas, que redimensionan su carácter privado y doméstico, y su específica ordenación, pensando, quizá, en actitudes que preludian los gabinetes y cámaras de maravillas del s. XVI. Otro aspecto igualmente destacable radica en su consideración más allá del valor exclusivamente material, al presentar las descripciones un notable interés por metales preciosos, y por su propia factura y $\operatorname{arte}^{54}$. Respecto a la procedencia de las piezas, hay que apuntar también como el tesoro de don Álvaro no solo se configuró a través de compras o regalos, sino también, mediante donaciones -como el caso de los bienes de María de Albornoz, biznieta y heredera del cardenal Gil Álvarez de Albornoz, que pasaron a manos del Condestable cuando esta falleció- ${ }^{55}$. Aunque el rey, incluso, fundió algunas de las joyas para rehacerlas y crear nuevas piezas ${ }^{56}$, lamentablemente, y como ya señaló Yarza, no se han conservado ni los joyeles ni las piezas sacras de don Álvaro de Luna ${ }^{57}$.

Junto al legendario tesoro de Escalona, el condestable tenía en su poder "la grand fazienda que fue suya de la cámara de los reyes viejos", ocultada por don Álvaro en el Alcázar de Madrid "en lo bajo del entre dos pilares", "que valía más de ochocientas

\footnotetext{
54 No obstante, Castillo Cáceres considera que el tesoro de don Álvaro, a pesar de poseer evidentes reminiscencias medievales, no estaba determinado por la piedras preciosas y los objetos suntuarios, como ocurría con tesoros medievales como el de Pedro I, definido esencialmente por las joyas y las gemas (sobre este, vid. H. GRASSOTI, "El tesoro de Pedro el Cruel", Archivo Español de Arte, 242 (1988), pp. 144-152). F. CASTILLO CÁCERES, "Innovación y tradición en Don Álvaro de Luna", Estudios sobre cultura, guerra y política en la Corona de Castilla (siglos XIV-XVII), Madrid, 2007, p. 136.

55 E. COOPER, Castillos señoriales de Castilla, Salamanca, 1991, I, p. 87; F. CASTILLO CÁCERES, op. cit., 1998 , p. 276 , nota 63 .

56 "Resçebió Alfonso de Illescas en la dicha cámara de Pedro de Astorga un collar de oro que fue del dicho maestre de Santiago el qual era fecho a manera de escarçelas que peso seis marcos e una onça e una ochava el qual dicho collar el dicho señor Rey mando desfazer e fundir con cient coronas de oro que dio gonzalo daua por mandado del dicho señor Rey este dicho dia al dicho Alonso de Illescas de las cuales se le fase aquí cargo al dicho Alfonso de Illescas que paso el dicho collar e las dichas cient coronas todo juntamente después de fundido siete marcos e seis onças e cinco ochauas de los qual se fizo por mandado del dicho señor Rey para su seniria la traer". J. FERRANDIS, op. cit., 1943, p. 24. Sobre la afición de Juan II por la platería, vid. M.V. HERRÁEZ ORTEGA, "De la plata y los plateros del rey Juan II de Castilla", Estudios de platería: San Eloy, Murcia, 2006, pp. 277-289.

57 J. YARZA LUACES, op. cit., 2003, p. 79. Según este autor existe una remota posibilidad de que se conozca algún objeto que le hubiera pertenecido, y hace referencia a un báculo de Aviñón de $c a$. 1342, que fue reformado ca. 1394 por voluntad de Benedicto XIII, el papa Luna (Madrid, Museo Arqueológico Nacional, inv. 52160), obra francesa en plata dorada y con esmaltes (J.M. CRUZ VALDOVINOS, Platería europea en España (1300-1700), Madrid, 1997, $\mathrm{n}^{\circ}$ 5, pp. 51-53). Aunque estuvo en poder de la familia Luna hasta finales del s. XIX, no resulta probable que estuviera en propiedad de don Álvaro ya que parece ser que nunca abandonó Aragón.
} 
mil doblas" y cuyo paradero dio a conocer al rey Juan II, Ferrand López de Saldaña ${ }^{58}$. Partidario de don Álvaro, había caído en desgracia siendo relegado de su cargo de Contador Mayor; pero tras la ejecución del condestable, hallándose en Navarra, y buscando el perdón real, la vuelta a su antiguo oficio y la devolución de sus bienes, comunicó el paradero del Tesoro de los Reyes Viejos de Castilla al monarca, compuesto por una gran variedad de piezas.

"Mandaron cavar e desfacer una pared entre los dichos pilares, fallaron treinta cuatro arcas muy grandes ensayaladas, e dentro dellas muy grandes riquezas, en especial veinte e cuatro Apóstoles grandes, los doce de oro macizos e los doce de plata, e un Santiago, e un Sant Francisco, todo de oro, e otras muchas cosas, e las espadas del Cid Ruy Díaz, Tizona e Colada, e la espada Guiosa, e una corona de oro del rey don Pedro, e una cinta de caderas, toda de oro e perlas e de piedras preciosas, que fue del Cid Ruy Diaz, e otras muchas cosas e piezas de plata e de oro, e de tantas labores que bien parescía valer lo que el dicho Ferrand López decía e más" ${ }^{" 59}$.

En relación a los libros, existió un ejemplar del Libro de las virtuosas e claras mujeres $^{60}$ (Fig. 2), que aparece entre los bienes de Isabel la Católica depositados en el Alcázar de Segovia e inventariados por Gaspar de Grizio en noviembre de $1503^{61}$ y que, probablemente, fue depositado allí por Juan II $^{62}$. Destaca por su rica encuaderna-

58 Fernán López de Saldaña es calificado por Fernán Pérez de Guzmán como "pequeño e raez onbre” (F. PÉREZ DE GUZMÁN, Generaciones y semblanzas, Buenos Aires, 1947, p. 68) y por Alonso de Palencia como "de origen oscuro pero de nobles prendas y brazo esforzado" (A. DE PALENCIA, Décadas, I, p. 17, citado por J. YARZA LUACES, op. cit., 2003, p. 41). Criado de don Álvaro de Luna desde 1428, es nombrado contador mayor por Juan II al año siguiente, obteniendo abundante patrimonio (J. DE MATA CARRIAZO, op. cit., 1940, p. 71). Sin embargo, en 1436 el rey lo manda prender, dejándole luego en libertad por intercesión del condestable. En 1453, el rey y don Álvaro están en Tordesillas, y después de asistir a misa en Santa Clara, conversan, alabando Álvaro la fidelidad del contador que contrapone a la traición de Alfonso Pérez de Vivero; afirmando además, que "dexó fundada una capellanía en aquel monesterio" (J. DE MATA CARRIAZO, op. cit., 1940, capítulo CV, p. 315). Fernán López de Saldaña construyó una amplia capilla funeraria en el monasterio de Santa Clara de Tordesillas en el lado de la epístola. Una inscripción indica que el contador inició los trabajos en 1430, sus cargos (camarero y canciller del rey y de su consejo) y la concluyó en 1435 . Una revisión cronológica de la misma, donde se aporta bibliografía, en F. VILLASEÑOR SEBASTIÁN, "Nuevas aportaciones a la historia constructiva de la capilla del contador Saldaña (Real Monasterio de Santa Clara de Tordesillas) (ca. 1430-1435) y su importancia en la renovación del gótico castellano", VIII Congreso Nacional de Historia de la Construcción, Actas, Madrid, 2013, pp. 1037-1046.

59 "Continuación de la Crónica de España del Arzobispo don Rodrigo Jiménez de Rada por el Obispo don Gonzalo de la Hinojosa", Colección de Documentos Inéditos para la Historia de España, t. 106, p. 136 (citado por J. FERRANDIS, op. cit., 1943, pp. XII y XIII).

60 J.M. FRADEJAS RUEDA, "Álvaro de Luna: Libro de las virtuosas e claras mujeres", C. ÁLVAR y J.M. LUCÍA MEJÍAS (eds.), Diccionario Filológico de Literatura medieval española. Textos y transmisión, Madrid, 2002, pp. 188-191, que incluye bibliografía sobre las ediciones y estudios de la obra. Sobre los aspectos artísticos véase la puesta al día en M.T. CHICOTE POMPANÍN y A. FUENTES ORTIZ, "El auctor de esta obra es el condestable don Álvaro de Luna. Génesis, iluminación y suntuosidad en las Virtuosas e claras mujeres", O. LÓPEZ GÓMEZ (coord.), Don Álvaro de Luna y Escalona. Poder, propaganda y memoria histórica en el otoño de la Edad Media, Toledo, 2013, pp. 171-212.

61 AGS, Patronato Real. Leg. 30-6. J. FERRANDIS, op. cit., 1943, pp. 69-169.

62 D.M. MÁRMOL MARÍN, Joyas en las Colecciones Reales de Isabel la Católica a Felipe II, Madrid, 2001, p. 454. 
ción con escudos de los Luna y veneras de plata, siendo uno de los pocos que, según Sánchez Cantón ${ }^{63}$, poseía la reina con una cubierta lujosa:

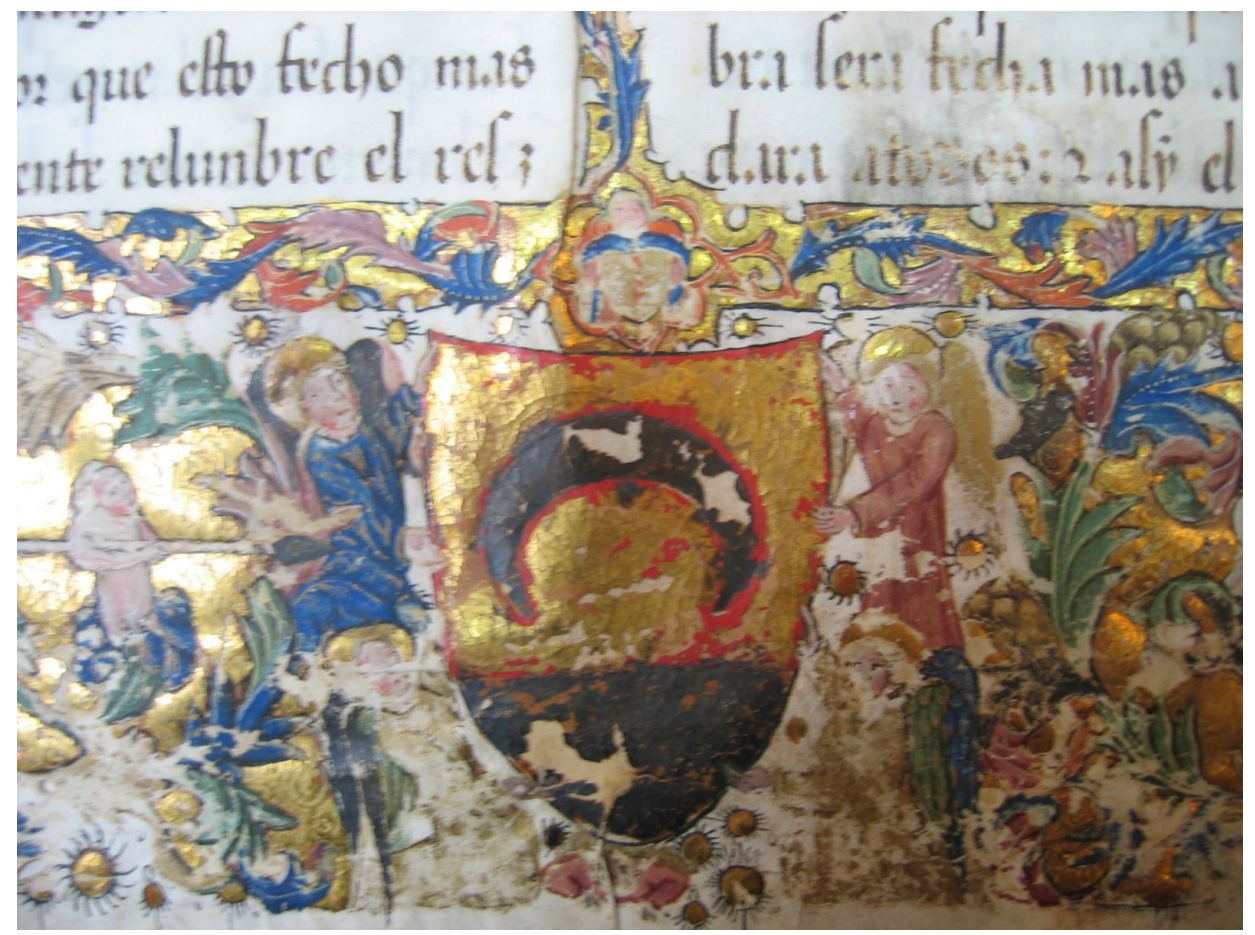

Fig. 2. Libro de las virtuosas e claras mujeres (Biblioteca de la Universidad de Salamanca, ms. 207, fol. 3r, detalle).

"otro libro de pergamino de mano que es de las virtuosas e claras mujeres que hizo el maestre don aluaro de luna con vna camisa de carmesí pelo forrado en tafetán azul y que tiene de cada parte vn quadro de plata dorado y esmaltado grande en que está vn escudo leonado las armas de luna e quatro veneras de plata dorada a los cantones e la vna venera de la vna parte esta suelta e tiene las charnelas e manos de las çerraduras de la misma plata con unas veneras e cruzes en dos textillos blancos e morados" $"$.

63 F.J. SÁNCHEZ CANTÓN, Libros, tapices y cuadros que coleccionó Isabel la Católica, Madrid, 1950, pp. 30, 50 y 51. Para este, debió ser el volumen perteneciente a Juan II, regalo del propio Condestable. Tanto él como Menéndez Pelayo (M. MENÉNDEZ PELAYO, "Advertencia preliminar" al Libro de las claras e virtuosas mujeres, Madrid, 1981, pp. V-XII) consideran que el ejemplar de la Reina Católica ricamente encuadernado con las armas de los Luna procedía de la Universidad de Salamanca, aunque ninguno plantea que perteneciera al privado, pasando a la biblioteca del rey tras la confiscación de los bienes. Para Castillo Cáceres (F. CASTILLO CÁCERES, op. cit., 2007, p. 129, nota 44) podría ser el origen del otro ejemplar existente en la Biblioteca del Palacio Real.

64 J. FERRANDIS, op. cit., 1943, p. 148. 


\section{Dotaciones religiosas}

El lamentable final de don Álvaro de Luna impidió completar el espacio funerario que este había mandado construir en la cabecera de la Catedral de Toledo ${ }^{65}$, no pudiendo "ornar la dicha capilla e la guarnecer de ornamentos"; labor que materializaba su viuda el 8 de mayo de $1484^{66}$. El Condestable ya había realizado ciertas donaciones de objetos suntuarios a significativos ámbitos religiosos. Antonio de Lalaing, acompañando a Felipe el Hermoso en su viaje a España en 1501, cuando el 6 de marzo, describe la iglesia de Santiago de Compostela, y detalla el tabernáculo que existía sobre la tumba del apóstol, afirma que "tiene de alto de doce a trece pies, y de ancho de diez a once, en el que hay algunas imágenes de plata. Encima del altar hay catorce imágenes de plata dorada, dadas por don Álvaro de Luna, en otro tiempo Condestable de Castilla" ${ }^{67}$.

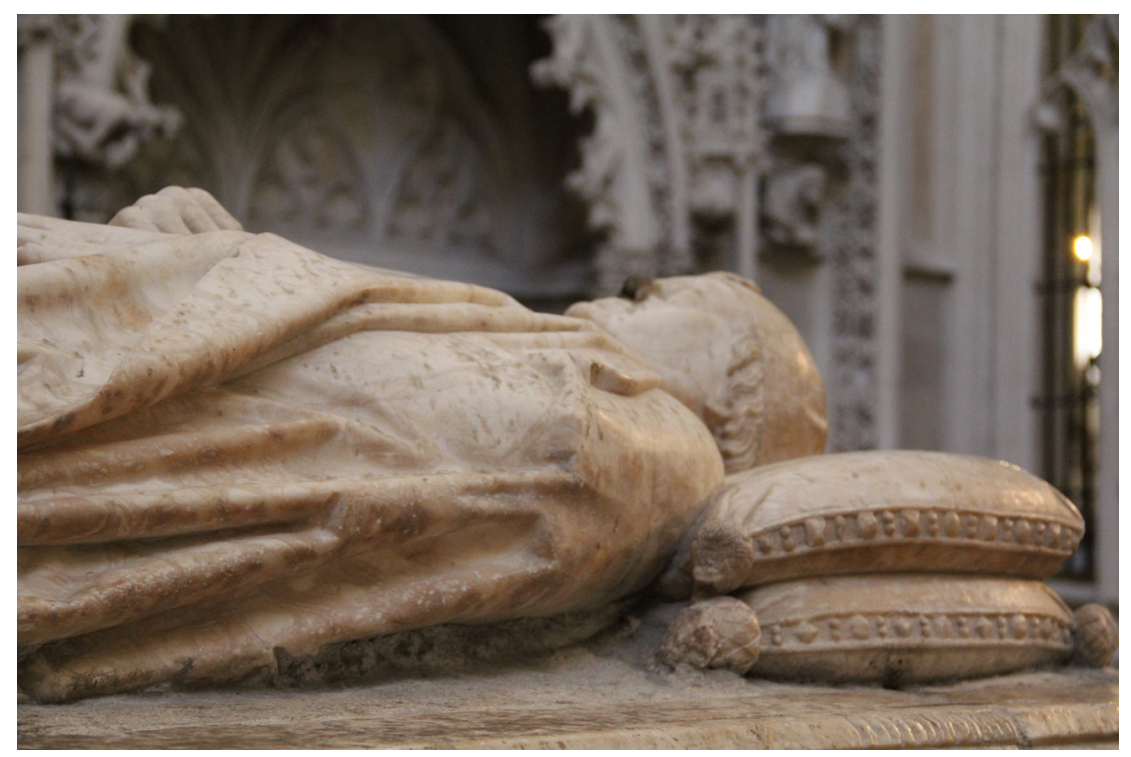

Fig. 3. Toledo, Catedral, Capilla de Santiago, Sepulcro de Álvaro de Luna (detalle).

65 Sobre esta, los más recientes estudios: E. FERNÁNDEZ GONZÁLEZ, op. cit., 1999, pp. 148-161; O. PÉREZ MONZÓN, "La imagen del poder nobiliario en Castilla. El arte y las Órdenes Militares en el tardogótico", Anuario de Estudios Medievales, 37 (2007), pp. 926-935. Sobre la importancia de la misma en la renovación del gótico final en Castilla, vid. B. ALONSO RUIZ y J. MARTÍNEZ DE AGUIRRE, "Arquitectura en la Corona de Castilla en torno a 1412", Artigrama, 26 (2011), pp. 139-142, y una síntesis sobre los principales trabajos acerca de la misma con bibliografía, en F. VILLASEÑOR SEBASTIÁN, " $L a$ mejor labrada e mejor casa y la más notable, rica e maravillosa capilla que habia en toda España: desarrollo artístico y arquitectónico en Castilla en tiempos de don Álvaro de Luna", O. LÓPEZ GÓMEZ (coord.), Don Álvaro de Luna y Escalona. Poder, propaganda y memoria histórica en el otoño de la Edad Media, Toledo, 2013, pp. 129-169.

66 AHN, Osuna, leg. 1734. Publicado por C. GONZÁLEZ PALENCIA, "La capilla de Don Álvaro de Luna en la Catedral de Toledo", Archivo Español de Arte y Arqueología, 13 (1929), pp. 112-118.

67 J. GARCÍA MERCADAL, Viajes de extranjeros por España y Portugal, I, Valladolid, 1999, p. 419. 


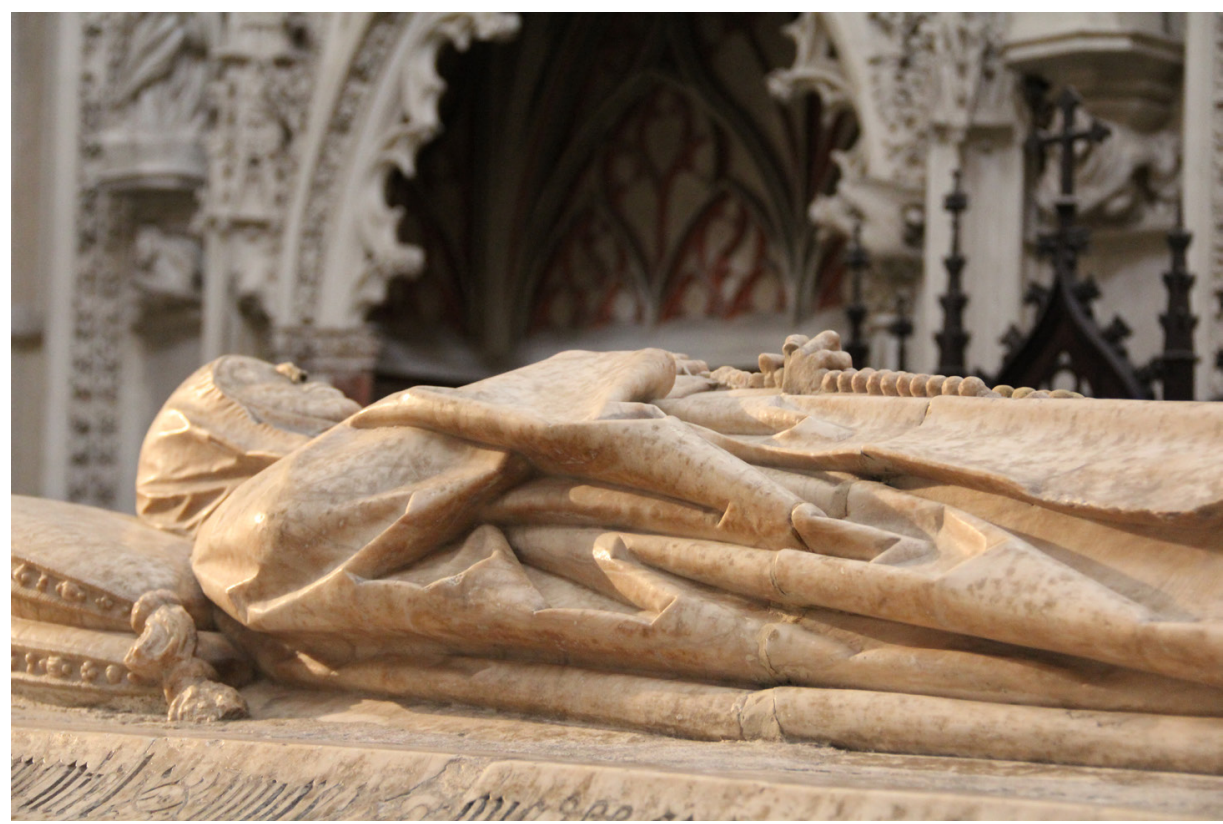

Fig. 4. Toledo, Catedral, Capilla de Santiago, Sepulcro de Juana Pimentel (detalle).

Sin embargo, en su caso, habrá de ser Juana Pimentel, la encargada de dotar la capilla funeraria (Figs. 3-5). El documento resulta un interesante testimonio por la exhaustividad en la que son descritas, junto a numerosos ornamentos litúrgicos, diversas piezas de orfebrería para los oficios litúrgicos:

"un calice todo dorado con su patena que pesa cinco marcos, el pie labrado con la estoria de la Pasión,

Otro calice que pesa tres marcos con su patena en el medio dorada, la copa e beuedero tanbien dorado e la mançana e quartos dorada, y el su ax asi mismo dorado,

dos candeleros de plata blancos que pesan tres marcos.

Vnas vinageras de plata blancas que pesan vn marco" $"$.

Y así mismo se insta al deán y cabildo a

"hacer reparar los ornamentos que yo agora doy a la dicha capilla, e por mi o otra qualquier persona en cualquier tiempo se dieren; los quales dichos ornamentos, e cosas e el paño de brocado que yo antes de agora tengo dado para que se ponga sobre la sepultura del dicho señor Maestre mi señor non sean sacados ni prestados fuera de la dicha capilla para onras ni para otra cosa alguna"69.

68 C. GONZÁLEZ PALENCIA, op. cit., p. 113.

69 Ibid., p. 115. 


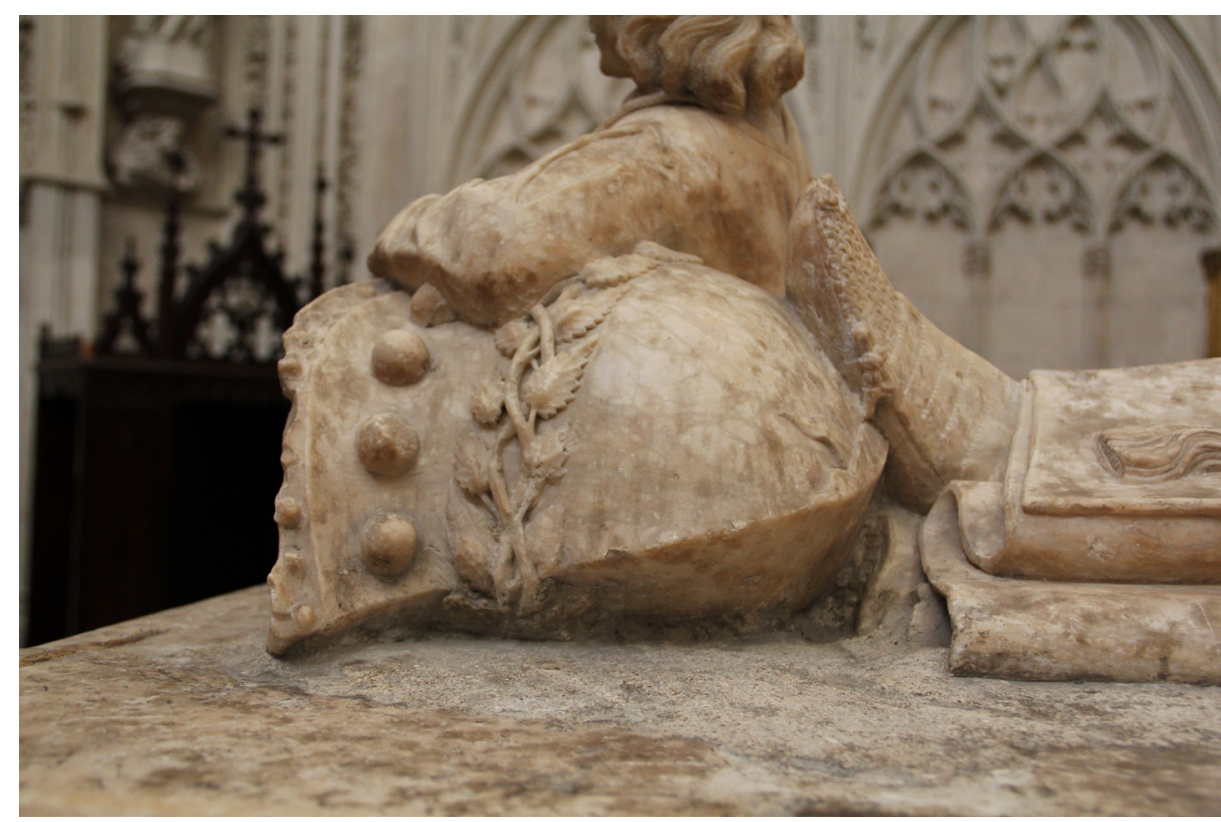

Fig. 5. Toledo, Catedral, Capilla de Santiago, Sepulcro de Álvaro de Luna (detalle).

Las referencias que Iñigo López de Mendoza, Marqués de Santillana, hace, en su Doctrinal de Privados, a los tesoros de don Álvaro de Luna resumen perfectamente, el triste destino que tuvo, al igual que su propietario, una de las más singulares colecciones de piezas suntuarias en la Castilla de finales de la Edad Media:

Vi tesoros ayuntados / por grand daño de su dueño. / Así como sombra o sueño / son nuestros días contados; / e si fueron prorrogados / por sus lágrimas a alguno, / d'éstos non veo uno / por nuestros muchos pecados.

¿Qué se fizo la moneda / que guardé para mis daños / tantos tiempos, tantos años: / plata, joyas, oro e seda? / Ca de todo no me queda / sinon este cadahalso. / Mundo malo, mundo falso, / no es quien contigo pueda ${ }^{70}$.

70 ÍÑIGO LÓPEZ DE MENDOZA, MARQUÉS DE SANTILLANA, Obras completas, Doctrinal de privados del Marqués de Santillana al maestre de Santiago don Álvaro de Luna (Salamanca, Biblioteca Histórica de la Universidad, ms. 2655), A. GÓMEZ MORENO y M.P.A.M. KERKHOF (eds.), I y V, Madrid, 2002. 